\title{
Sustaining mentoring relationships on-line
}

\author{
D. Kevin O'Neill \\ Ontario Institute for Studies in Education \\ University of Toronto \\ 252 Bloor St. W. \\ Toronto, Ontario M5S 1V6 Canada \\ (416) 923-6641 x2531 \\ dko@acm.org
}

\author{
Louis M. Gomez \\ School of Education and Social Policy \\ Northwestern University \\ 2115 N. Campus Dr. \\ Evanston, IL, 60208 USA \\ (847) 467-2821 \\ l-gomez@nwu.edu
}

\begin{abstract}
CSCW systems and research aim to sustain productive relationships over barriers of time and space. For the most part, however, the CSCW literature has focused on shortterm relationships or collaborative episodes. Here, we examine in depth 26 lengthy email relationships between students in grades 7 to 12 and volunteer scientists who advised them on science projects. We illustrate the unique dynamics of these relationships, consider their technical and social demands, and discuss the potential for CSCW systems to help sustain long-term help relationships by better accommodating their needs.
\end{abstract}

\section{Keywords}

CSCW, help, long-term relationships, mentoring, telementoring

\section{INTRODUCTION}

The central goal of CSCW systems and research is to sustain productive relationships over barriers of time and space. Recent research in the field has examined the shortterm help exchanges that can be supported by CSCW systems, revealing a critical interplay between the dimensions of the helping task, its associated roles, and the technical affordances which keep these exchanges socially viable [1]. Despite a growing interest and investment in the longer-term helping relationships which can be supported by $\mathrm{CSCW}$ systems, however, little attention has so far been paid to them in the research literature. We will begin filling this void with an analysis of data from an in-depth study of email-based mentoring relationships.

The relationships under study here took place between 90 teen-aged and pre-teen science students and volunteer scientists from across the United States and Canada. Each relationship continued for a period of up to nine weeks and revolved around an ill-structured intellectual task: designing, carrying out and reporting a science project. As we will discuss below, the email-based mentoring that we have documented shares some of the influences discussed by Ackerman et. al., but has unique dynamics of its own which present unique technical and social demands. Using several examples from telementoring dialogues, we will elucidate these demands and discuss the potential for CSCW systems to better sustain long-term help relationships by accommodating them.

\section{Mentoring Relationships}

While successful people often point to the importance of mentoring relationships in their development [2], these relationships are quite sensitive to time and space constraints. Since they often arise out of informal communications, they can be hampered by a variety of incidental factors such as office locations [3], preventing people who might excel as mentors from serving in this capacity. Where the spatial organization of the workplace is not an obstacle, mentoring activities may be hampered by daily schedules and organizational surroundings. Thus, while programs do exist which link school and work settings $[4,5]$, these programs have not become widespread because the different schedules on which schools, corporations and universities operate make it difficult to maintain relationships across these organizations.

\section{From Mentoring to Telementoring}

In response to the problems described above, researchers have begun actively orchestrating mentoring relationships on-line. Over the past three years, "telementoring" has become an active field of development in which a significant financial investment is being made [6-8]; however, reporting on the dynamics of these relationships and their implications for CSCW has been sparse.

Our research began in response to the practical challenges of providing students with sufficient guidance for ambitious, long-term science projects [9]. For the past five years, a teacher collaborator of ours has taught a project-based high school Earth Science class which attempts to motivate traditional science avoiders by offering them greaterfreedom to study phenomena that interest them. In this class, small teams of students conduct lengthy investigations into any natural phenomena they please, "so long as they are not living - that's Biology." The teacher imposes strict requirements on the methods and reporting of students' research, but the coverage of particular content is not required.

In Greenberg, S. and Neuwirth, C. (eds.), Proceedings of CSCW 98: ACM conference on computersupported cooperative work. November 14-18, 1998. New York: Association for Computing Machinery. 
While the teacher may be familiar with most of the phenomena that his students choose to study, he may not always be up-to-date on the current state of research in the field or the latest Internet resources available for study. During the year that this research was conducted, for instance, a group of young women became intrigued with the controversy over the swimming motions of an aquatic dinosaur called the plesiosaur. Other challenging project ideas that year included differentiating black holes from other radiation sources in space. While these were clearly worthwhile subjects for study, the teacher's own intellectual resources were insufficient to provide for his students' needs. In each case, volunteer telementors recruited via the Usenet ".sci" hierarchy were able to help guide the projects to satisfying conclusions.

Over a period of three years, we have helped hundreds of volunteer scientists, including university faculty, graduate students and a variety of applied scientists, offer guidance to high school and middle school science students for just a few minutes each week, entirely via email. News of our work sometimes meets with a skeptical reaction from those wondering where we could possibly be finding a sufficient number of qualified people to volunteer their time. For those skeptics, Table 1 presents a profile of our mentor pool, broken down by profession.

\begin{tabular}{|l|r|}
\hline Profession & $\%$ \\
\hline Professional (engineer, consultant) & 34 \\
\hline Master's student & 31 \\
\hline University faculty & 23 \\
\hline Doctoral student & 7 \\
\hline Undergraduate student & 3 \\
\hline Postdoc & 2 \\
\hline
\end{tabular}

Table 1: Professions of a sample of 90 volunteer telementors

Census data on voluntarism [10, 11] and conservative estimates of the number of college graduates with access to email at home [12] suggest that the available volunteer workforce for telementoring in the U.S. and Canada could be as large as 2.9 million people. This number is small by comparison to the number of K-12 students in the two countries, but the ratio ( 1 potential volunteer to every 17 students) is promising when one considers that telementoring is inappropriate for many ages of students, subject-matters and styles of teaching.

\section{RESEARCH QUESTIONS AND METHODS}

With additional development, we hope to see telementoring become a widespread application of CSCW in K-12 education. However, as our analysis below will make clear, this cannot occur with the present state of know-how in the field.

The question of whether any particular implementation of telementoring "works" in an educational sense is too complex to be addressed within the scope of this paper (it is explored at length in [13]). Here we will concern ourselves solely with the social-technical design issues surrounding how telementoring can be made satisfying enough for all participants to ensure their continued involvement.
As mentioned earlier, one of our teacher collaborators has been carrying out telementoring on an ongoing basis for a number of years, with little external support. Through close study of his mature implementation and attempts to reproduce it, we hoped to answer the following questions:

- What personal motives and social dynamics govern telementoring activity?

Understanding what people desire from this activity and the ways in which they may be prevented from getting it will help determine the practicality of sustained telementoring activity in other settings and on a larger scale.

- How feasible is it to organize telementoring for many people at a time (rather than as a boutique program)?

Many people find telementoring an enticing idea, but doubt its practicality at a large scale. Greater knowledge of the dynamics which govern telementoring activity will help establish reasonable expectations for more widespread use.

- What social and technological supports are most needed to sustain telementoring?

Having understood the motives of the participants in telementoring and the dynamics which govern it, we may be able to identify bottlenecks which specifically designed or tailored CSCW systems may alleviate.

Given these questions and concerns, our research followed a diagnostic strategy which capitalized on the natural variation in the development of telementoring relationships to tease out the most limiting social and technical factors. Our data collection began with broad-based surveys of the 90 students for whom we had orchestrated telementoring relationships. A survey instrument based on classroom observations and preliminary interviews by O'Neill was used to assess the degree of students' satisfaction with their telementoring relationships and the factors leading to it. This instrument was administered at the completion of each telementored project: a total of three times in the high school class, and once in the middle school.

Using these data, we constructed a stratified sample of relationships judged to be satisfying, mediocre and unsatisfying. For every project, 4-6 teams of target students were interviewed in their project groups for roughly 45 minutes apiece. Interviews were also conducted with a number of telementors involved in relationships at all three strata. These data assisted in the interpretation of automatically generated email logs, coded according to an inductively-developed scheme representing the topics raised in the messages.

\section{ORCHESTRATING TELEMENTORING}

Unlike the ephemeral help exchanges examined by Ackerman et. al., telementoring is very difficult to achieve without purposeful orchestration. In the two classrooms involved in this research, orchestration work was primarily performed by the teacher. As the first step, students are assigned to work in research teams of 1 to 5 when conducting their long-term science projects. In both settings, students had a high degree of control over the domains they studied and/or the research emphases they chose. This created a strong need for the guidance that 
telementors can provide. In the high school environment, students conducted three projects in a row, each seven weeks or more in length, and each with a different mentor. In the middle school, students did one lengthy project in which they had the flexibility to craft a specialty within a larger piece of research designed by the teacher.

Once the student teams identified their research domains and/or emphases, they were matched by their teacher with a volunteer mentor with some expertise in this area. For the most part, these volunteers were recruited through postings to Usenet groups such as sci.astro, sci.geo, and sci.environment. A typical recruiting posting read:

Mentors Needed for Research Based Earth Science Class

I am a high school Earth Science teacher. Our school is involved in a NSF grant project at Northwestern University....

I am looking for oceanographers, astronomers, meteorologists and geoscientists (and grad students) to act as "Mentors" for various student projects. These mentors would assist my students in their explorations, not by giving answers and spending lots of time explaining basics, but by asking questions about the research, the data collection, and/or the methods. They might provide insight to data collection or interpretation. Basically, to help keep the kids on the track that I am laying down for them, and hopefully providing professional expertise/insights when appropriate. We're sort of modeling this on the graduate type of thesis research project, which is familiar to all of you in some form anyway. I'm hoping this will not be a time intensive kind of involvement.

If you are at all interested in helping, please respond by email, and I will send you more detailed information.

Respondents to these postings received lengthier messages describing the teacher's school and students, the nature of the projects for which volunteers were needed, the sorts of difficulties students typically faced in this work, and the time commitment expected of volunteers. If they wereready to participate at that point, the teacher matched them with a team of students, and the relationship began.

While we had developed our own educational groupware product [14], we chose the low-tech approach of email in our initial experiments because the wide variety of computing platforms in use by our volunteers necessitated a lowest-common-denominator strategy. However, this approach had the collateral advantage of bypassing the introduction of software formalisms at an early stage [15], allowing for careful requirements-gathering. In fact, the only nonstandard piece in our technological setup was a custom-built email routing process which circulated messages reliably amongst all the members of a research team and their mentor, sent copies to the teacher if needed, and archived copies for later analysis. This mail router was later incorporated into a larger web-based application designed to streamline the management of telementoring for teachers. We will discuss this system and its functions at a later point in the paper.
As one might expect given the ill-structured nature of the task, both telementors and students needed substantial guidance concerning the kinds of help they should provide and expect. The guidance provided in our designs took several forms, including a limited amount of direct instruction to students about courteous email and the bounds of reasonable requests. However, the most important form of guidance we provided to both students and telementors consisted of "activity structures" describing the intellectual products expected from students (research questions, data sets, data analysis plans, etc.), the schedule on which they were due, and the responsibilities of all participants with respect to these. The activity structures played an important role in shaping and bounding the online relationships, ensuring that to the greatest degree possible, they contributed to classroom work rather than devolving into unproductive chat.

\section{A SAMPLE RELATIONSHIP}

A brief example will illustrate the nature of these telementoring relationships. This example does not represent the best relationship we have studied, nor the worst; but it highlights some of the important general influences on telementoring in an economical fashion. These influences include:

- The types of utility provided by telementoring (an important part of which is timeliness)

- The visibility of protégés' work to their mentors

- Participants' sensitivity to their roles and the limits of those roles.

Three high school students ( 2 male, 1 female) had decided to conduct a research project on forest fires started by lightning. Like all the students in their class, they were required to formulate a nontrivial research question about this phenomenon which could be addressed through some form of numerical data analysis, rather than simply by consulting references. Having chosen their general topic, however, the students quickly got bogged down in a fruitless web search for numerical data that would allow them to pose a more specific research question. As a result, they missed their deadline to propose a research question to their teacher. Finding themselves in crisis, they urgently looked to their mentor, Bruce, for advice:

\section{Dear Bruce,}

We tried to contact the lady that has all the information relating to lightning and forest fires, but she did not write us back. Our situation is now pretty brutal: we don't really have a specific question (because we can't find any data), our paper is due in a little over a week, and if this lady doesn't talk to us, we have no more leads to follow and we will have to start from scratch. If there is any way possible for you to think of another aspect of lightning to study and write about, we are in desperate need. We especially could use something that won't take a month to gather all the research on. Thanks for all your help and effort.

Note that from the beginning, the students' relationship with Bruce focused on a practical problem of some 
intellectual depth. The students were not simply asking for answers to factual questions or "information" about lightning which they might locate elsewhere, but were appealing for suggestions toward a viable research agenda. Since it was clear that expertise, not information, was the critical bottleneck to their performance, they could see the productive utility of the relationship with their mentor and were willing to invest effort in developing it.

The students' candid report of their predicament was also vital to the success of this relationship, providing needed visibility. In fact, in nearly every successful relationship we observed, mentors appeared to rely upon regular, honest status reports to provide the grist they needed to size up their protégés' current goals and the difficulties they were facing. Without this knowledge, it was difficult (if not impossible) to formulate the subtle mid-course corrections that constitute the core of telementoring activity. Bruce's next messages illustrate this type of advice.

Bruce responded to his protégés' request in a very timely fashion the following day, suggesting two possible research agendas and data sources appropriate to them. His message illustrates some of the most important kinds of advice that a telementor can offer, given sufficient knowledge about a students' project:

Good morning,

Did you look at the web site I mentioned in my last message? It contains the 1995 fire statistics, noting cause and state. That's about the best data you can get on-line, I suspect. If you can then find data on either the acres of forest in each state (should be relatively easy to find) or the population density in each state, you can look at some comparison of the $\%$ of fires started by lightning and the population density, or the forested area.

Taking the population density issue, you should be able to get state populations from either an atlas or the U.S. Census Bureau (I'm pretty sure they have a web site). State areas should also be easy to find. With this info. and the fire statistics, you could easily calculate $50(\mathrm{x}, \mathrm{y})$ pairs of coordinates where $\mathrm{x}$ and $\mathrm{y}$ are the population density and the $\%$ of fires started by lightning. (Which of these would be the dependent and which the independent variable?)

Do you know about least-squares fit, or linear regression? Do you expect to find that \% lightning fires increases as pop. density increases, or should \%LF decrease when pop. density increases? Does a linear regression agree with what you expect?

With his assertion that the web site he recommended had about the best relevant data on-line, Bruce immediately saved his protégés a lot of fruitless web searching. The productive utility of this advice was very clear to the students, and probably helped keep them involved in the relationship. Bruce also offers direction by presenting not one, but two reasonable research agendas concerning the empirical relationship between variables associated with forest fires. One of these agendas (concerning the percentage of lightning fires in an area and its population density) was apparently a favorite of his, and he described an elaborate plan for pursuing it. This plan would still take considerable initiative for students at this level to carry out, so Bruce was not simply "giving answers away".

At this point, days passed with no further communication. Then the team committed to a research question and reported its decision to Bruce. Surprisingly, they had not chosen to follow the research agenda that he had so clearly laid out for them; instead, they focused their attention on the relationship between lightning fires and the forested area in a state. Bruce's response shows his clear regard for his role and its limits. Far from being irritated by their choice, Bruce reinforced it and did his best to help them follow through on their new plan. He did, nonetheless, remind them of other avenues of investigation still open:

Glad you've got a topic, finally! I checked a couple of sites that I thought would list the acres of forest for the 50 states, but neither panned out. I have three options for you:

1. Call the Forest Inventory and Analysis office of the Forest Service at (202) 205-1343 and ask if the data is on-line. If it is, they should know.

2. Email me again with a fax number and I can fax you some pages that will list "acres protected" of forest and rangeland, which is a column that normally appears next to those on the lightning-data web page

3. Do population density, not forested area. I suspect there'll be a stronger correlation, and the population of the U.S. states should be quite simple to find (look in a road atlas if you can't find the Census Bureau's web page).

In an important way, visibility is at play in this message, too. Bruce's advising strategy of presenting options and standing back is adaptive for someone who is knowledgeable about students' project goals and their research domain, but has limited knowledge of their full capabilities, their commitment to their work, or the resources available to them. As the forest fires team moved forward with its project, Bruce presented options and expressed informed opinions, but did not attempt to issue commandments or usurp the teacher's role as the ultimate arbiter of worthy project ideas. In other words, he respected the bounds of his role. His protégés appreciated his advice and took advantage it, yet they did not follow it slavishly.

\section{PATHS OF TELEMENTORING RELATIONSHIPS}

The forest fires project was, of course, just one of many telementoring relationships that have occurred in the two participating classrooms, and cannot be taken as representative. As in other instances of electronic help exchanges, including the Zephyr help instance [1] and Usenet news, our telementoring relationships varied considerably in their helpfulness to the participants, and at times they failed altogether. The CSCW design challenge is to understand the various paths that long-term telementoring relationships can take, and find ways to maximize the positive outcomes. In this section, we will provide a brief overview of the various paths that our telementoring relationships followed, and why. Later 
sections will discuss possible design solutions to the problems described below.

The simplest measure of telementoring activity is, of course, the number of messages exchanged by the participants in a relationship. Figure 1 shows the total volume of email messages exchanged by 59 student teams in the two classes and their assigned mentors. As is obvious, the majority of these relationships did not involve a large quantity of correspondence. While the total number of messages was over 40 in one case, the median number of messages per relationship was only 9 .

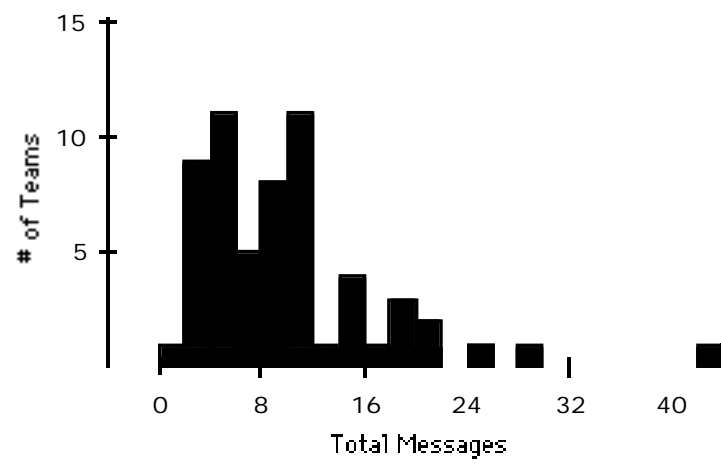

Figure 1: Volume of messages exchanged by 59 student teams and their mentors

While large and small volumes of email are one useful indicator of students' and mentors' engagement, however, they do not correspond in any reliable way to the success or failure of those relationships. It can be the case, for instance, that a student team only needs one crucial piece of advice to launch its project, which is taken care of in an exchange of four or five messages with a telementor. Alternatively, messages can be fewer in number but very involved. For instance, one of the deepest student-mentor research collaborations of 1995/96 (detailed in [13]) involved the exchange of only 15 email messages, spread over a period of 9 weeks.

To get a clearer sense of the variety of relationships we orchestrated, a detailed topical coding of all the logged email (representing 26 relationships) was produced using QSR NUD*IST [16], a qualitative data-analysis software package. This coding became quite detailed, with a total of 32 hierarchical categories. Among the high-level topics of dialogue that emerged from the coding were:

- students' project ideas (questions to answer, hypotheses to test, or simply topics to learn more about)

- the status of students' work (what students have done, how far along they think they are in their projects)

- domain phenomena under study (e.g. earthquakes)

- specialized terminology

- learning resources (books, journals, web sites, etc.)

- research methods (including choice and analysis of data)

- scientific practice in general

On the basis of this coding, we characterized three broad categories of telementoring dialogues: abortive, perfunctory, and interest-driven partnerships. Below, we will briefly discuss each of these categories, their prevalence, and their implications for the design of technical and social systems for sustainable telementoring.

\section{Abortive dialogues}

While nearly all of the telementoring dialogues we analyzed $(92 \%)$ involved some mention of students' ideas for their science projects, many fewer $(65 \%)$ progressed as far as raising specific domain-related phenomena for deeper discussion. We characterize the balance of the dialogues $(35 \%)$ as "abortive" because they were apparentlyabandoned by the participants. Interviews suggested a variety of causes for this abandonment. In a few cases, the telementor was simply unresponsive to the students: often due to an absence from work. In other cases, students were unable to articulate their needs well enough to get the dialogue started, contacted their telementors too late for them to provide timely guidance, or failed to invest any effort in the relationship because it seemed to them to be a waste of time.

In any sustainable model of telementoring, the frequency of abortive relationships must be kept below a certain threshold; though this threshold will be unique to circumstances and participants. While our volunteer mentors generally appreciated that not all students are well motivated to study science, and that each volunteer received "the luck of the draw" when matched with students, abortive relationships generate frustration for telementors and waste the teachers' administrative effort. The greatest concern about these relationships from the designer's standpoint is that too many might cause substantial attrition from the volunteer pool, thus threatening the viability of telementoring in the long term.

\section{Perfunctory dialogues}

A step up from abortive dialogues were topic-driven ones in which students treated their assigned mentors essentially as research librarians. As in a brief consultation with a librarian, students' contributions to the perfunctory dialogues consisted primarily of factual questions or requests for references to data or articles. If telementors satisfied these requests routinely and failed to build a deeper form of participation in students' work (such as an influence over the research agenda or the methods employed in pursuing it), they could be left with little control over how the relationships developed, or whether they continued. In the worst case, students might decide to "take the goods and run". Take, for instance, this exchange between two young men and a geologist at the U.S. Geological Survey:

Subject: flood help

Hi, Richard, We are two students doing a project on

floods. We are looking for some concrete data to observe. Our teacher said that you might be able to help. We have access to the web, so if you know of any good web cites we would love that. Thanks for your time.

Sincerely, Ken and Cody

Subject: Re: flood help 
If you are interested in studying Illinois floods, the web site you will want to look at is

"http://wwwdilurb.er.usgs.gov/pub/floodinfo/", which maintains both historical and real-time flood (and other streamflow) data for Illinois rivers.

You will also want to browse the US Geological Survey homepage, which is at "http://www.usgs.gov/". Note the link at that page to water resources, which will lead you to a wealth of flooding information for sites and events all over the country.

Let me know how else I can help, especially with your study design and/or interpretation of the field data.

\section{Richard}

While Richard was clear in his desire to offer advice on the study design and data interpretation, his protégés' next and final message was simply to inform him that their project was finished:

\section{Subject: final paper}

Richard,

Cody and I would like to thank you for all of your help on our floods project. We also apologize for a lack of keeping in touch. The net sites that you told us about, the USGS ones, were absolutely great and helped a lot. thanks again. We also thought you might want a copy of our paper so here it is.

Thanks,

Ken and Cody

Despite his clear interest in the students' work, Richard was simply shut out of the bulk of the project activity. Even if he had wanted to take a proactive role in the project, he could not have, because he simply had no idea what the students were up to (i.e. zero visibility). Thankfully, the case described above is the only recorded instance in which students discussed resources to the total exclusion of other matters important to their shared work with their mentor, such as constraints like project deadlines, time on-line, their background knowledge, etc. These issues were raised in $31 \%$ of the dialogues.

Like abortive dialogues, these perfunctory dialogues are of concern to the designer because they are not likely to provide the rewards that bring volunteers back to telementoring. They may, however, offer utility to students and teachers in the short term, and this makes them especially dangerous to the long-term sustainability of telementoring.

\section{Interest-driven partnerships}

Looking only at the above types of relationships, one might get a poor impression of telementoring. However, a considerable proportion of the relationships we studied developed beyond a simple focus on resources for study, broaching topics such as specialized terminology (42\%) or broader issues of scientific practice (15\%). These dialogues more closely approached the ideal of a research partnership. As an example, below are excerpts from an exchange between a telementor and a research team beginning a project on sea surface temperatures. As the conversation begins, the students are relatively directionless in their work, having already begun and abandoned a project on riverbeds:

Subject: Re: Hi

Dear Byron and Vanessa,

$>$ We are two high school students in an earth

$>$ science class researching sea surface temperatures.

$>\mathrm{We}$, if we can find any data, are going to research

$>$ the question: How do the temperatures in

$>$ the Northern Atlantic and Northern Pacific compare?

$>$ And try to find a reason for this. If you have any

$>$ questions, comments, pointers, or anything else, we

$>$ would be grateful to hear about it!

You have chosen an interesting topic. Where are you in your research now?

A lot of data exist on sea surface temperatures (SSTs). Compiled data sets of historical measurements from ships are one data source. Another data source is satellite data.

An introductory textbook on general oceanography (e.g., Grant Gross's _Oceanography:_A_View_of_the_Earth_) would be a good place to do some of your initial research.

\section{Regards, David}

We should note that in his first message, David contributes to the team's productivity without being merely compliant. While he provides some reinforcement of the students' research agenda and offers a pointer or two, he also makes a bid for greater visibility by asking Byron and Vanessa immediately for a report of their progress to date. Not only does he get this report, but his mentees actually defer to his judgement as to how they should continue:

Subject: We are...

Hey David, currently we are working on finding places on the web where we can find out data about oceans and their temperatures. One site I found to be useful was a site from a Japanese company (not that I remember the name or anything...). But I found it very helpful. We need to re-write our Background Information (on oceans/their temperatures and how they are controlled). But this can wait until next week (unless you think we should do it now). So thanks a lot,

Byron and Vanessa

Subject: Re: We are...

Dear Byron and Vanessa:

I would start writing ASAP. Writing often takes longer than you think it will.

The Levitus `94 data set has global ocean temperatures and salinities as a function of latitude, longitude, and depth. You can access it at:

http://ingrid.ldgo.columbia.edu/SOURCES/.LEVITUS94

Another site that may be helpful to you is (perhaps it's the Japanese site you mentioned?): 
http://dpo.ori.u-tokyo.ac.jp:81/ocean/toolmap/Levitusmap.html

It not only has a link to the Levitus '94 data set, it allows you to specify what parts of it you want to look at (e.g., only North Pacific SSTs).

Enjoy, David

It took Byron and Vanessa several more messages to settle on a research question they were content with, but throughout this time they remained engaged in their relationship with David. This sustained conversation gave David natural opportunities to offer advice on writing reports ("start ASAP"), and guidance to data sources and analytical tools. Because the students made much of their progress and their thinking visible to David, he was able to offer a greater variety of guidance than mentors in perfunctory relationships.

Arguably, the most highly developed relationships were those that involved the discussion of research methodology $(27 \%)$. For example, one student team which had been attempting to grow several varieties of crystals sought advice on how to recover from the apparent failure of their experiments. In order to secure advice from their telementor, they found it necessary to explain what they had done, and their reasons for doing it, in considerable detail:

Dear Kevin,

We tried to make crystals using powdered sugar, regular white sugar, brown sugar, and salt (we couldn't get epsom salt) we mixed 2 tablespoons $(30 \mathrm{~mL})$ of all the solids with $150 \mathrm{~mL}$ of tap water 'till all the solid was dissolved. Then we tied string to a popsicle stick and put it on the glass so that the string was hanging in the liquid. This was about four days ago, but there are only crystals in the salt and it looks like there's mold or something in the powdered sugar and in the regular sugar. Did we use too much water? I used that much water so that there would be a lot of string in liquid. Should we try again or wait 'till all the water evaporates? we're also going to do the same thing only put the beakers in shade, light, cold, and on a hot plate to see if darkness, heat, etc. has any effect on crystal growth. I know that the crystals on the hot plate will grow faster but do you have any suggestions on what we should do with the beakers we've already mixed? should we use less water for the other experiments? --Katie

Katie's message is a nice example of a circumstance in which students engaged their telementors as a helpful and critical audience. Katie invests effort in making her team's work visible to her mentor, not because she was compelled by her teacher to do so or was trying to impress anyone, but because she needed her mentor to understand the team's predicament in order to secure informed advice.

\section{SUSTAINING FORCES}

As we mentioned above, one of the teachers involved in this research has been orchestrating telementoring relationships for several years now on a largely independent basis. As other teachers become involved in similar efforts, it is worth considering the sustaining forces behind such early, successful implementations of telementoring.

\section{Productive Utility}

First and most obvious, telementoring relationships have productive utility for students, often helping them "get into position to think" about their research and steering them toward more manageable investigations. This is a substantial benefit, since settling on a research agenda is frequently the most time-consuming and least productive stage of project work. Without their mentors' attention and advice, it is clear that a greater number of teams would flounder or languish in their work for longer periods.

From a whole-classroom perspective, students avoiding unproductive floundering also has motivational utility that is of particular value to the teacher. Since the teacher's time is at a premium during the agenda-formation stage of students' projects, students are most likely to be frustrated in their demands for advice and guidance at this time. A scarcity of timely guidance not only reduces students' productivity, but generates frustration which in turn might threaten the viability of the whole project-based approach to teaching. Thus, the additional support of telementors is of value to the teacher in maintaining students' motivation to participate in projects.

Altogether, though a proportion of telementoring relationships always fizzle or fail (depending upon the implementation and the participants' expectations), volunteers' effort allows both teachers and students to channel their efforts more selectively. The time and effort that telementors save the teacher in offering guidance and searching for resources to support students' work can be reinvested in guiding other students who need additional help. The quality of guidance provided to the class as a whole is therefore improved.

\section{Lightweightedness}

Like Zephyr help exchanges, telementoring relationships are typically "lightweight" for the volunteers: often requiring as little as fifteen minutes of time invested each week. All the same, these brief moments can provide volunteers with unique opportunities to break from their routine work and contribute something worthwhile to the future of their chosen field. Students' projects can also present opportunities for mature practitioners to stretch themselves beyond their customary job roles or expertise in a way that can be quite stimulating. As a Physics graduate student explained after guiding three students through their project on black holes:

I really enjoyed it, and for me it was great. I'd be sitting down, coding all day, writing [computer] programs, and I'd be able to take [a] break every couple of days to answer this email and look up something that I wanted to learn about. ....The main thing was that it was something that I could use when I needed a break. I mean, that's really the way I looked at it. ...You know, I can go spend a half an hour learning about something else I enjoy. 


\section{LIMITING FACTORS}

What path a telementoring relationship will follow cannot be predicted in advance, even by teachers familiar with both their students' capabilities and their volunteers' expertise. However, several issues discussed above and raised repeatedly in interviews with students and telementors offer explanations for the failure of specific relationships and point to key design considerations.

\section{Low Visibility}

As we discussed above, it is difficult for a rich telementoring relationship to develop under conditions of low visibility. One enthusiastic volunteer who had been faced with uncooperative protégés suggested that advising students via email could be "very much working in a black box." This sentiment was shared by her protégés, who complained that telementors:

...have no idea what you're doing, what you've been doing, what you've gone through, what you haven't gone through. They've got no clue. ...personally the way I see it is if they're not stepping through the project with you, they've got no idea what you've already done, and I don't like repeating myself very much.

Telementors clearly suffer by comparison to the relatively instant gratification that is provided by classroom teachers when they are readily available. As the same pair of students complained:

A: It's like one thing if you've got like a teacher, but it's another thing if you're trying to talk to someone...

B: Over the computer. And it's like you wait for the response. And by that time you did something else! And then you know, it's like writing about what you did in the past, and when you get the response it's already done.

These students were not the most dedicated in their class, but they do point to a tough design problem for telementoring. If a mentor's guidance is to be helpful, it must be timely; and timely, pertinent advice relies on the kind of visibility that can only be based on routine review of students' work, such as a teacher does when circulating in a classroom.

Since email-based telementoring relationships do succeed, it is clear that some students are capable of furnishing adequate visibility even in as unsupportive a medium as email. Teachers assist this effort indirectly through the activity structures and daily shepherding they provide. In the ideal case, however, telementoring would not rely quite so much on students' facility as regular correspondents. Instead, visibility would be produced by a more supportive electronic discourse environment and a classroom culture that honors the production of status documents in electronic form. We will revisit this possibility in the "Design Implications" section below.

\section{Concern with "Too Much Help"}

The lack of visibility endemic to email-based mentoring not only makes offering guidance difficult, but it can exacerbate volunteers' natural concerns with providing "too much help" to their protégés. Detailed case studies of individual telementoring relationships [13] revealed the important influence that both mentors' and students' concerns over this issue had on the development of both successful and unsuccessful telementoring relationships. In some instances, mentors' worries led to an unfortunate "teasing" dynamic in which the students made what they believed to be reasonable requests, only to be rebuffed with the assertion that "I know the answer to your question, but I don't think I should tell you." In such cases, students may suspect their telementors of egotism or simple meanspiritedness, wondering: "if he didn't want to help us, why did he volunteer in the first place?"

\section{Sociability and Developmental Readiness}

While the relationships we are discussing here are meant, first and foremost, to contribute toward curriculum goals, our interviews with volunteers make it clear that they derive greater satisfaction from their efforts by "getting to know the kids". In a roundabout way, sociability also contributes to the productivity of the relationships by helping participants' build confidence in one anothers' good intentions, and by opening doors to collateral learning opportunities. In both of the classrooms discussed here, we have seen volunteers present students with an "insider's view" of a field of work which would be rare for students to encounter at school.

In the middle school classroom, dialogues turned much more frequently to students' non scholastic interests and telementors' hobbies or home lives $(67 \%)$ than it did in the high school classroom (17\%). In part, this difference was a consequence of the different activity structure implemented in the middle school, which required the exchange of personal biographies as a first step to establishing the relationship. However, interview data make it clear that our high school students would likely have presented resistance to this strategy. In the quotation below, two young women express their confusion over the motives of volunteer mentors:

A: I don't see why they would want to [volunteer]. I mean personally, it's not like you're going to make a new friend. I have some weird feeling that our mentor expected us to be friendly.

B: Buddy-buddy.

A: Yeah, 'cause we were fairly businesslike. They were like, "give a brief description of yourself." And we were like, "students, this school, this age. Anyway, back to what we really need."

While this is not a representative attitude, differences in the sociability of students present serious concerns about how to most sustainably implement telementoring. As the cases discussed above illustrate, no telementoring relationship can succeed without students' active engagement; yet because mentoring relationships are developmental in nature [2] students may simply not be equipped to anticipate or appreciate the potential benefits of telementoring as they begin it. We might refer to this as the "developmental catch-22".

Survey data collected at the end of each of the three high school projects in 1995/96 shed some light on the 
implications of the developmental catch-22, showing that it is not necessarily fatal. With more experience of telementoring, students' expectations appear to become more reasonable.

Among the items on our closing survey was a 7-point Likert scale on which students rated their satisfaction with the telementoring experience. Figure 2 shows project-toproject changes in the distribution of these satisfaction ratings for 22 students who had a mentor for every project. For clarity, these ratings are grouped into three categories: "Happy" (5 to 7), "Neutral" (4), and "Unhappy" (1 to 3).

Note that the number of "unhappy" respondents, the largest single group at the end of Project 1, drops steadily throughout the year. This change in project-to-project satisfaction suggests, as do our interview data, that students developed substantially more reasonable expectations of telementoring over the course of a year. Alternative designs discussed in the next section may make it possible to "bootstrap" students into more reasonable expectations even more quickly.

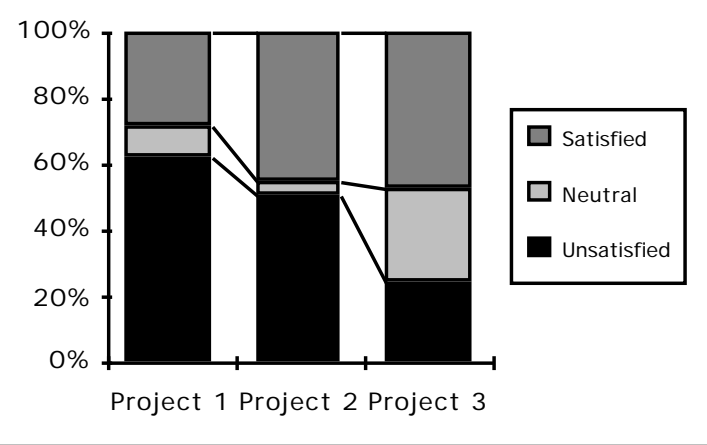

Figure 2: Students' agreement with the statement, "Overall, the mentoring was a success for me"

\section{DESIGN IMPLICATIONS}

This research points to several needs for sustained telementoring, associated with both CSCW systems and routines for their use in classrooms.

\section{Developing understanding of mentoring}

Because of the developmental catch-22, understanding the nature and potential rewards of mentoring is not a trivial matter, even when it is connected to practical tasks. And, while students and telementors can benefit from some upfront preparation for their roles, nothing will better enable them to make the most of the opportunities presented by telementoring than more experience of it.

In the best design, students and mentors would have the opportunity to be involved in several telementoring relationships per year. Another, less demanding approach is to provide opportunities for participants to observe other mentoring relationships while building their own. In a recent design experiment in three high school classrooms in Toronto, an educational groupware product called Knowledge Forum [17] was used to orchestrate telementoring relationships in a public discourse space. While formal matches were made between students and mentors, and compartments were set up within the environment to separate project topics, participants were encouraged to (and did) read the dialogues between all the mentors and students.

While one might have expected participants to resist the lack of privacy involved in this arrangement, both mentors and students responded positively to the opportunity to selfmonitor their performance relative to others and emulate the best practices they observed. This type of arrangement therefore holds promise for reducing the proportion of relationships which are aborted by students who simply cannot anticipate the potential benefits of investing effort in the relationship.

\section{Increasing visibility}

As we made clear above, an important requirement of sustainable telementoring is that volunteer mentors see enough of their protégés' work to provide informed advice. It is also important for mentors' satisfaction that they understand how they contributed to students' work. As one volunteer put it, "I would have been more gratified to know what problems the students had that I was helping them to solve. It's kind of like if you're tutoring math, you want to know how the kid did on the exam afterward."

One way to address the visibility problem is through the use of groupware products like Knowledge Forum which might make more of students' routine work accessible to telementors. However, if the system is not to be seen as creating extra work, the curriculum and classroom culture must privilege the production of literate records of learning to assist local tasks, as well as sharing them with external collaborators.

Minimizing management and preserving goodwill Observation of the teaching practice surrounding telementoring [13] suggests that if it is to be practical for more teachers, the greatest technical need is for services to streamline teachers' effort, make maximum use of volunteers' available time, and preserve volunteers' goodwill. In the long run, Usenet will not be a feasible way to locate large numbers of volunteer telementors, and organizing their effort will be too organizationally intensive for most teachers without new tools.

In response to this problem, we have built a Web-based application to serve the needs of teachers seeking telementors, mentors looking for volunteer opportunities, and students involved in telementoring relationships. This system, called "the CoVis Mentor Database", performs several functions:

- It provides a centralized database of volunteers (recruited by a school board or local community organization), which teachers can search by mentors' expertise, teaching experience, and other criteria.

- It offers an expedient way for teachers to solicit a large number of potential volunteers from the database at once. Forms prompt teachers for the details of a project which have most often been requested by volunteers in the past.

- When volunteers agree to participate in a particular project, they are "checked out" of the database, to prevent them from receiving further requests until their current 
mentor relationship ends. They can also log in at any time to make themselves temporarily unavailable for mentoring.

A more sophisticated and customizable version of the system is under development at OISE/UT. We hope to make this system inexpensive enough and simple enough to use that corporations and school boards will be able to run their own "mentor databases" to support a variety of community-based telementoring projects.

\section{CONCLUSION}

In our experiments, telementoring has served as a practical means to support ambitious project-based science learning in grades 7-12, and cost-effective staff development and educational outreach in adult workplaces. For this CSCW practice to reach more settings and be sustainable, however, two key social-technical requirements must be met. First, students' work needs to be made more visible to volunteer mentors than seems likely with email alone. Mature tools already exist to fill this need, and further experiments are needed to test their appropriateness for telementoring. Second, teachers must have appropriate organizational tools to reduce the management overhead that telementoring now requires. These tools, which we have begun to develop, can not only make telementoring more practical for teachers, but help preserve volunteers' goodwill as well.

\section{ACKNOWLEDGMENTS}

Rory Wagner of New Trier High School in Winnetka, Illinois and Judith Lachance-Whitcomb of Jordan Community School in Chicago were invaluable collaborators in this research. We thank them and their students for their contributions. We also gratefully acknowledge the support of the National Science Foundation under grant \#RED-945729 and the Illinois State Board of Education. This research continues in collaboration with the CSILE/Knowledge-Building team at the Ontario Institute for Studies in Education of the University of Toronto, with support from the James S. McDonnell Foundation and the Natural Sciences and Engineering Research Council of Canada.

\section{REFERENCES}

1. Ackerman, M.S. and L. Palen. The Zephyr help instance: Promoting ongoing activity in a CSCW system. in CHI 96: Conference on human factors in computing systems. (1996), New York: Association for Computing Machinery.

2. Kram, K.E., Mentoring at work: Developmental relationships in organizational life. (1985), New York: University Press of America.

3. Fish, R.S., Kraut, R. E., Root, R. W. \& Rice R. E., Video as a technology for informal communications. Communications of the ACM (1993) 36(1): p. 48-61.

4. Waltner, J.C., Learning from scientists at work, Educational Leadership (1992) p. 48-52.

5. EDC, Industry volunteers in the classroom: Freeing teachers' time for professional development. (1994) Educational Development Center, Inc., 55 Chapel Street, Newtonville, Mass., 02158-1060.
6. Bennett, D.T., et al. Telementoring: Designing on-line mentoring environments for high school women in science and technical courses. in Joint National Conference of the Women in Engineering Program Advocates and the National Association of Minority Engineering Program Administrators.

(1997) Washington, DC.

7. Harris, J., The Electronic Emissary. (1997) [on-line]: http://www.tapr.org/emissary/

8. Neils, D., The Hewlett-Packard e-mail mentor program (1997) [on-line]: http://mentor.external.hp.com/

9. Wagner, R., Expeditions to Mount Everest, in Tales from the electronic frontier: First-hand experiences of teachersand students using the Internet in K-12 math and science, R.W. Mayumi Shinohara, Art Sussman, Editor. (1996) WestEd: San Francisco.

10. Ross, D.P. and E.R. Schillington, A Profile of the Canadian volunteer: A guide to the 1987 Survey of Volunteer Activity in Canada. (1988, November) National Voluntary Organizations: Ottawa, Canada.

11. Hayghe, H.V., Volunteers in the U.S.: Who donates the time? Monthly Labor Review. (1991, February) p. 17-23.

12. Anderson, R.H., et al., Universal access to e-mail: Feasibility and societal implications. (1995) Santa Monica, CA: RAND.

13. O'Neill, D.K., Engaging science practice through science practitioners: Design experiments in $K-12$ telementoring. (1998) Unpublished doctoral dissertation, Northwestern University.

14. O'Neill, D.K. and Gomez, L.M. The Collaboratory Notebook: A networked knowledgebuilding environment for project learning. in Ed-Media '94: World Conference on Educational Multimedia and Hypermedia. (1994) Vancouver, BC, Canada.

15. Bowers, J., The politics of formalism, in Contexts of computer-mediated communication, M. Lea, Editor. (1992), Harvester Wheatsheaf: New York. p. 232-261.

16. QSR, NUD*IST. (1997), Scolari: Thousand Oaks, CA.

17. Learning in Motion, Inc., Knowledge Forum. (1997) Learning in Motion: Santa Cruz, CA. 